Revista de Estudios Histórico-Jurídicos

[Sección historia del derecho público]

XLIII (Valparaíso, Chile, 2021)

[pp. 187-199]

\title{
¿Un acuerdo constitucional? El Pacto de San SEBASTIÁN COMO FUNDAMENTO DE LA INSTITUCIONALIDAD AUTONÓMICA REPUBLICANA DE 1931 SEGÚN LAS FUENTES TESTIMONIALES
}

[A Constitutional Agreement? The Pact of San Sebastian as grounds for the 1931 Republican Autonomous Institutional Structure for Governance according to Testimony Sources]

\author{
Enrique San Miguel Pérez* \\ Universidad Rey Juan Carlos, España
}

\section{RESUMEN}

El 17 de agosto de 1930 las fuerzas políticas que propugnaban el establecimiento de la Segunda República española, incluyendo tantos a los partidos republicanos como antiguos líderes monárquicos, se reunieron en San Sebastián para establecer una alianza estratégica que facilitara la transición de la monarquía a la república. Los delegados de las fuerzas catalanistas participantes, sin embargo, solicitaron que se explicitara la adhesión de los suscriptores del acuerdo al reconocimiento de un régimen de autogobierno político para Cataluña. Ello representó la adquisición de un compromiso constituyente que habría de plasmarse en la Constitución española de 9 de diciembre de 1931.

\section{Palabras clave}

España - Constitución - Segunda República - Pacto de San Sebastián - Cataluña - Autonomía.

\section{ABSTRACT}

On 17 August 1930, the political actors advocating for the establishment of the Second Spanish Republic, including both the republican parties as well as the formal monarchical leaders, gathered at San Sebastian to establish a strategic pact to facilitate the transition from the monarchy to the republic. The delegates of the Catalan actors to the Pact, however, requested that there was explicit mention that the signatories to the Pact were thereby recognizing a selfgovernment political regime for Catalonia, which meant undertaking a constituent commitment that subsequently took the form of the Spanish Constitution of 1931.

\section{KEY WORDS}

Spain - Constitution - Second Republic - Pact of San Sebastian - Catalonia - Autonomy.

RECIBIDO el 26 de abril de 2021 y ACEPTADO el 11 de junio de 2021

* Catedrático de Historia del Derecho y de las Instituciones. Facultad de Ciencias Jurídicas y Sociales. Universidad Rey Juan Carlos. Paseo de los Artilleros S/N. 28032. Madrid. España. Dirección electrónica: enrique.sanmiguel@urjc.es ORCID 0000-0003-0600-5876. 


\section{LA ESTRATEGIA DEL CONSENSO POLÍTICO PARA EL ACUERDO CONSTITUYENTE}

REPUBLICANO

"En esta reunión quedó acordado emprender una activa campaña para derribar la Monarquía aprovechando el malestar que se dejaba sentir en todos los órdenes de la vida nacional, aceptando todas las colaboraciones revolucionarias, fueran o no republicanas [...] 'Según me dicen -terminaba el informador- todo ha quedado prendido con alfileres, no obstante lo cual, todos ellos se las prometen muy felices. Di cuenta de estos hechos al ministro de la Gobernación y presidente del Consejo, pero, a decir verdad, en aquella ocasión ni ellos ni yo concedimos gran importancia a los acuerdos. Tanto es así que el 23 acompañé al general Berenguer a Santander, donde estaba reunida parte de la Escuadra [...]"1.

A decir verdad, no fue únicamente el director general de Seguridad del gobierno Berenguer, o el propio presidente del Consejo de Ministros, por no hablar del rey, quienes no otorgaron demasiada atención ni importancia a la reunión celebrada en el local de la Unión Republicana de San Sebastián el 17 de agosto de 1930, y de la que el propio Emilio Mola no tuvo información hasta transcurridos tres días, el 20 de agosto siguiente. Pero sí que en ámbitos más enraizados en la realidad española pudo llegar a pulsarse la histórica dimensión de los acontecimientos que se produjeron en el apacible estío de aquel año.

En 1973, el novelista Edward Goodman confirmaba la recuperación de su nombre el año precedente (en la novela Aurora de sangre: vida y muerte de Hildegart, llevada al cine en 1977 por Fernando Fernán Gómez) para publicar un extenso y meditado libro denominado 1930. Historia política de un año decisivo. Reapareció entonces para siempre Eduardo de Guzmán, el joven director de los periódicos cenetistas La Tierra, La Libertad y, sobre todo, durante la Guerra Civil, Castilla Libre, cuyo último número apareció el 31 de marzo de 1939.

Eduardo de Guzmán fue, también, casi el postrero intelectual republicano en salir de Madrid, desde luego el último periodista, abandonando su domicilio en el último piso del último número de la Calle de La Magdalena, al lado de la histórica Farmacia El Globo, en el comienzo de la Calle Santa Isabel y de la Plaza de Antón Martín, mientras las vanguardias del ejército vencedor subían por la Calle Atocha camino de la Plaza Mayor. El escritor nacido en Villada de Palencia habría de relatar su odisea vital en unas escalofriantes memorias en forma de trilogía integradas por La muerte de la esperanza (publicada ese mismo año 1973), El año de la victoria (1974), y Nosotros, los asesinos (1976), narrando la penosa marcha de los vencidos hacia el exilio a través del puerto de Valencia, que habría de ser después el de Alicante, y finalmente ninguna parte, traicionados por los barcos que nunca llegaron a un muelle en el que de manera regular secas detonaciones anunciaban un nuevo suicidio, capturados por los italianos, entregados a las tropas de Franco, y confinados en el mortífero y siniestro campo de Albatera. Unas penalidades que se convirtieron en el preludio de un simulacro de juicio, una condena a muerte después conmutada y revocada por una sentencia a cadena

\footnotetext{
${ }^{1}$ Mola Vidal, Emilio, Obras completas (Madrid, Librería Santarén, 1940), p. 382.
} 
perpetua, y años después la salida de la prisión para ganarse la vida como escritor de novelas del Oeste.

Eduardo de Guzmán, casi todavía Goodman, un analista siempre escéptico, agudo y equilibrado, como buen ácrata castellano, llamaba al lector a dedicar su atención a uno de los más decisivos años de la historia española. Porque, advertía, su interpretación estaba ya condenada a la exageración, y no al rigor, y tanto por parte de los monárquicos, empeñados en demostrar que la Corona estaba perdida en 1930, y nada pudieron hacer ellos por evitar su derrumbamiento, como por los republicanos, que tendían a considerar que la Segunda República era un clamor ya en 1930, pero gracias a su trabajo y tesón ${ }^{2}$. Eduardo de Guzmán, sin embargo, recordaba la fuerza de partidos comprometidos con la monarquía parlamentaria, como la Lliga de Françesc Cambó, todavía en 1930, y también el fracaso de las sublevaciones republicanas en Jaca y en Cuatro Vientos, y consideraba que la brutal crisis de 1929, y la muy española propensión a creer que un mero cambio de gobierno habría de permitir superarla, habían operado como factores mucho más eficaces y determinantes que la conjunción de las fuerzas republicanas en la caída de Alfonso XIII.

Pero sí que Eduardo de Guzmán reconocía, y en toda su relevancia, que un acontecimiento político muy cualificado había permitido que la crisis general del sistema pudiera expresarse políticamente a través del proyecto republicano: el acuerdo concertado por la mayoría de las fuerzas y sensibilidades republicanas democráticas en San Sebastián el 17 de agosto de 1930. Un acontecimiento por muchos de sus contemporáneos inadvertido, pero que, en opinión de Guzmán, contaba con un protagonista excepcional por su equilibrio, su realismo, su inteligencia, y su lucidez, y quien habría de convertirse en el arquitecto del gobierno provisional de la Segunda República: Miguel Maura y Gamazo.

El hijo republicano de Antonio Maura carecía sin duda de la colosal estatura de su padre, una de las más grandes figuras en la historia constitucional española, y el fundador del amplio conservadurismo popular y de clases medias del siglo XX. Pero el magisterio que había disfrutado familiarmente habría de desplegarse, y con enorme autoridad y resolución, tanto estratégica como ejecutiva, a la hora de diseñar y materializar un plan político e institucional pragmático, inteligente, resolutivo y nítido. El plan asumido por todos los asistentes a la reunión de San Sebastián. Un plan con aliento constituyente, y nutrido por compromisos políticos, territoriales y organizacionales cuya interpretación inmediata habría de hacer posible un cambio político pacífico, sereno e inspirado por el sentido institucional.

${ }^{2}$ De Guzmán, Eduardo, 1930. Historia política de un año decisivo (Madrid, Tebas, 1973), pp. 12-13: “[...] Con muy pocas excepciones, tanto los monárquicos -Berenguer, Mola, duque de Maura, Romanones, La Cierva, marqués de Hoyos y un largo etcétera- como los republicanos y socialistas -Lerroux. Miguel Maura, Alcalá Zamora, Prieto, Largo Caballero, etcétera- se creyeron obligados a exponer, más para las generaciones futuras que para sus contemporáneos, su visión y su intervención especial en los acontecimientos. Aunque a priori es justo admitir la buena fe de todos y su honestidad en la narración de los hechos, a posteriori tropezamos con enormes contradicciones entre lo afirmado por éste y aquel, muchas veces militantes en la misma tendencia $[\ldots]$ ". 
El diseño constituyente de Miguel Maura partía de una concepción integradora y de unidad de las energías democráticas, es decir, de las ideas con las que el maurismo había querido reformar e impulsar el sistema constitucional de la Restauración. En su célebre Discurso de V alladolid de 18 de enero 1902, inminente la proclamación de Alfonso XIII, su padre Antonio Maura había plasmado ya su concepción de estadista, superadora de la histórica fractura política que durante casi un siglo de experiencia constitucional había erosionado muy severamente la fortaleza de la institucionalidad liberal. Una fractura nacida de la incapacidad de las fuerzas actrices de la política española para entender la alternancia en las responsabilidades de gobierno y el compromiso institucional dentro de un marco constitucional compartido, y no desde la voluntad de expulsión del adversario de la vida pública: "Se había hecho la paz entre la extrema derecha y la extrema izquierda en la Constitución de 1876 y en las leyes políticas subsiguientes; pero era menester empezar a vivirlas, y estrenar los hábitos de ciudadanos, los cuales tampoco se estrenaron durante la revolución de septiembre, que no fue en la realidad, aunque proclamase doctrinas democráticas y liberales, más que un imperio de las facciones de la izquierda, como antes habían imperado las facciones de la derecha $[\ldots]^{\prime \prime 3}$.

Miguel Maura habría de traducir las líneas maestras del maurismo para dotar al proyecto republicano de un guion unitario. De acuerdo con la perspectiva de quien habría ser el primer ministro de Gobernación de la Segunda República española, el objetivo de la reunión que comenzó en San Sebastián a las tres de la tarde del 17 de agosto de 1930 era nada menos que conjugar todas las fuerzas republicanas, y singularmente las representativas de las clases populares, dentro de una estrategia y una acción política unitaria, creando las bases para la designación acordada y compartida de los integrantes del futuro gobierno de la nación. Nada más pragmático y más ejecutivo. Y, sin duda, en la medida en que el acuerdo se plasmó enteramente, un objetivo que habría de adquirir una dimensión que excede la mera conjunción política táctica. Un privilegiado contemporáneo de los hechos y uno de los más grandes escritores españoles del siglo XX, como Josep Pla, no tendría la menor duda sobre la naturaleza del Pacto de San Sebastián como acta de nacimiento de la Segunda República, y la determinante responsabilidad de la siempre muy singular personalidad de Miguel Maura en su suscripción ${ }^{4}$.

${ }^{3}$ Maura, Antonio, Treinta y cinco años de vida pública (Madrid, Biblioteca Nueva, 1954), pp. 224-225.

${ }^{4}$ PLA, Josep, Dietarios de Madrid. Madrid, 1921. El advenimiento de la II República (Barcelona, Destino, 2020), p. 284: "De todos los elementos del Gobierno republicano (Pacto de San Sebastián), el que me parece destinado a actuar de una manera más eficaz es el señor Maura. Es un hombre muy bien vestido (americana cruzada que contrasta con la descuidada vestimenta de los otros elementos del Gobierno provisional), muy bien peinado, pero de una mentalidad extremadamente alocada [...]". Vid. igualmente Maura, Miguel, Así cayó Alfonso XIII (Barcelona, Ariel, 1966), p. 70: “Quienes actuábamos en la vida política con la mirada puesta en el porvenir de España y palpábamos las reacciones, no siempre pacíficas y caritativas, que la visión del próximo porvenir suscitaba en ciertas masas populares, vivíamos bajo la obsesión de llegar cuanto antes a encuadrar las fuerzas políticas y sindicales dentro de un programa previamente madurado, y además designar a los hombres que habrían de asumir, llegado que 


\section{El autogobierno político de Cataluña como COMPROMISO CONSTITUCIONAL}

Un acuerdo cuyos protagonistas representaban a la inmensa mayoría de las fuerzas políticas que habrían de verse integradas en el Gobierno provisional de la inminente República, reunidos bajo la presidencia de Fernando Sasiaín, presidente del Círculo Republicano de San Sebastián: Niceto Alcalá-Zamora y Miguel Maura, por la Derecha Liberal Republicana; Alejandro Lerroux, por la Alianza Republicana; Marcelino Domingo, Álvaro de Albornoz y Ángel Galarza, por el Partido Radical Socialista; Manuel Azaña, por Acción Republicana; Santiago Casares Quiroga, por la Federación Republicana Gallega; Manuel Carrasco i Formiguera, por Acció Catalana; Matías Mallol, por Acció Republicana de Catalunya; Jaume Ayguader i Miró, por Estat Catalá; Indalecio Prieto, como militante del Partido Socialista Obrero Español, si bien la organización no decidió personarse partidariamente hasta conocer el resultado de la reunión; Felipe Sánchez Román y Eduardo Ortega y Gasset a título de invitados; y con Gregorio Marañón como ausente, pero habiendo enviado un telegrama de adhesión.

Se trataba de una amplísima representación de todas las fuerzas tradicionalmente republicanas, como radicales, socialistas, y radical-socialistas, de los nacionalismos periféricos, y de los sectores liberales encuadrados dentro de la lógica política y constitucional de 1876, pero también comprometidos con su reforma, más o menos profunda, que a partir de 1923 se habían desvinculado de una monarquía ya no parlamentaria, y decidido sumarse a una conjunción republicana que en San Sebastián adquiría la forma de una gran coalición cívica muy central, que comprometía, a través de Indalecio Prieto, a las organizaciones sindicales y de clase más importante, pero también a la derecha democrática de procedencia monárquica a través de Niceto Alcalá-Zamora y del propio Miguel Maura.

El programa maurista adquiría, de esta forma, una validez pre-constituyente, tanto en sus grandes lineamientos políticos y estratégicos, como jurídicos e institucionales. Miguel Maura es rotundo cuando afirma que, sin el amplio acuerdo alcanzado en la urbe guipuzcoana, los acontecimientos que se desarrollaron a partir de las elecciones municipales del 12 de abril de 1931, y muy especialmente en Barcelona, hubieran escapado a cualquier forma de actuación coordinada y arruinado el programa republicano, por no hablar de sus consecuencias para la paz y la concordia cívicas ${ }^{5}$.

fuese el momento, la función de gobernar. De la tónica de aquel programa y de la calidad de estos hombres dependería, íntegramente, la suerte del país. Se trataba, en una palabra, de preparar la colchoneta en la que había de caer fatalmente el cuerpo nacional cuando llegase la hora del cambio de régimen. Este fue el objetivo principal de la reunión de San Sebastián, objetivo felizmente logrado [...]".

${ }^{5}$ Ibíd., p. 72: "Fue el Pacto de San Sebastián, sólo él, lo que permitió al Gobierno Provisional $[. .$.$] prevalecer frente a las desbordadas pretensiones que, al instante de proclamada la$ Republica, exteriorizó don Francisco Maciá sobre la autonomía inmediata y total de Cataluña, sobre la designación de gobernadores y alcaldes [...] Si acabé prevaleciendo [...] fue gracias a la existencia previa del Pacto de San Sebastián. Sin él, los primeros días de la República hubiesen sido catastróficos para la paz de España [...]". Coincide su hermano y adversario desde el 
Miguel Maura tenía muy presente el comportamiento de los representantes de las fuerzas catalanistas en la reunión celebrada en la capital donostiarra. Rafael Sánchez Guerra, enlace de Niceto Alcalá-Zamora con el republicanismo barcelonés en el año previo a la caída de la monarquía, y también interlocutor natural del Comité Republicano ante su padre, don José Sánchez Guerra, y los nada casualmente denominados constitucionalistas, partidarios de una salida precisamente constituyente de la monarquía de Alfonso XIII a través de una refundación del sistema parlamentario conforme a las grandes corrientes políticas dominantes en las monarquías subsistentes en la Europa de 1930 (por cierto, con la excepción de Francia, Alemania, Austria, Checoslovaquia y el Estado Libre de Irlanda, todas las democracias supervivientes en el continente eran monarquías), recuerda cómo estando en Barcelona con Lluis Nicolau d'Olwer (tan querido para la Historia del Derecho) apenas cuatro meses después, la noche del levantamiento de la guarnición de Jaca, y leyendo el manifiesto revolucionario del pronunciamiento a más de cincuenta representantes de las fuerzas republicanas catalanas, fue amablemente reconvenido por el final vibrante y solemne del texto -“Viva España con honor"- negándose tanto Nicolau d'Olwer como el propio Ayguader i Miró a firmarlo. Pero Sánchez Guerra se mantuvo firme, y terminó consiguiendo el respaldo de todos los asistentes ${ }^{6}$.

Alejandro Lerroux, por el contrario, se muestra en sus muchas veces sorprendentes memorias sumamente desdeñoso con la situación que se planteó, y no digamos con la reacción de Miguel Maura y de Álvaro de Albornoz ${ }^{7}$, y concentra su valoración de la histórica reunión en descubrir los titánicos esfuerzos de Niceto Alcalá-Zamora para apartarle de toda forma de futuro protagonismo en el liderazgo del Gobierno provisional, así como del propio republicanismo español, en el que sin duda se encontraba encuadrado mucho antes que el futuro presidente del Gobierno provisional y jefe del Estado, un extremo que habría de quedar ya establecido en el propio Pacto de San Sebastián.

Todos los testimonios, sin embargo, y comenzando por el del propio Miguel Maura, apuntan a que su metódico diseño se topó, al comienzo de la reunión vespertina del 17 de agosto, con un inesperado obstáculo. Tan pronto se reunieron los delegados de las fuerzas republicanas, Manuel Carrasco i Formiguera,

campo monárquico, Gabriel Maura, $c f r$. Duque de Maura; Fernández Almagro, Melchor: Por qué cayó Alfonso XIII (Madrid, Ediciones Ambos Mundos S. L., 1948), p. 391.

${ }^{6}$ SÁnchez Guerra, Rafael, Proceso de un cambio de regimen. (Historia y murmuración) (Madrid, Compañía Ibero\&Americana de Publicaciones S. A., 1932), pp. 50-51: "Mire, este grito de 'Viva España con honor' es una cosa arcaica y no conviene ahora darlo en Cataluña. Sería major que lo cambiásemos por otro viva cualquiera. Yo, por mi significación política, tan catalanista, no puedo autorizar con mi firma este manifiesto, si no se suprime este final [...] Lo demás me parece muy bien [...] Ya comprenderá que yo me debo a un partido y a una tradición bien conocida de todos".

${ }^{7}$ Lerroux, Alejandro, La pequeña historia (Madrid, Afrodisio Aguado S. A., 1963), p. 56: "A los pocos momentos advertí que 'la obra que se iba a representar' estaba ensayada para algunos, para todos no. Por ejemplo, cuando los catalanistas expusieron las condiciones en que prestarían su concurso, Albornoz y Maura no pudieron contenerse. Fui yo quien tuvo que enseñarles cómo se lidiaban aquellas fieras". 
en nombre de Acció Catalana, reclamó que, con carácter previo al comienzo de las deliberaciones, se reconociese que la proclamación de la República española determinaría "la más absoluta autonomía para Cataluña", obteniendo "su derecho a la autodeterminación”. Miguel Maura no puede ser más terminante en sus memorias a la hora de emitir su valoración cuando afirma que "a este desatino, sucedió un silencio general y penoso" ". Pero es evidente que el objetivo general, es decir, el establecimiento de un acuerdo de todas las fuerzas congregadas en San Sebastián para su ordenado y pacífico acceso a las responsabilidades de gobierno y la apertura de un proceso constituyente, quedaba severamente mediatizado por las aspiraciones expresadas por el abogado barcelonés, que se convertía en el inesperado protagonista político, pero también constituyente, de la reunión.

\section{Manuel Carrasco i Formiguera: un testimonio histórico-jurídico} único del pacto de San Sebastián y de su validez constitucional

La historia de Manuel Carrasco i Formiguera y la del socialcristianismo catalán, más allá del muy notable libro de Francesc Canosa ${ }^{9}$, o de los históricos testimonios de figuras como Joan Sales, sin duda uno de los primeros escritores españoles del siglo XX, y quien en una carta al gran poeta ilerdense Màrius Torres desde Monegrillo, en pleno frente de guerra durante la contienda civil, el 17 de mayo de 1937, consideraba al separatismo como una "idea mezquina"10, requiere aún un examen monográfico, y desde ambas orillas del río Ebro. Es cierto que la contrariedad de los congregados en el local de la Unión Republicana de San Sebastián tras la intervención inicial del jurista barcelonés fue enorme. Pero Niceto Alcalá Zamora, con el tono solemne que siempre le caracterizó, considera que, después de la aspereza de la intervención inicial de Manuel Carrasco i Formiguera, se consiguió un acuerdo histórico que, sin prejuzgar, en buena lógica, la actuación de las Cortes constituyentes, sí que acertaba a definir sus líneas maestras ${ }^{11}$. Cabe afirmar que, en

${ }^{8}$ Maura, Miguel, (cit. n. 4), p. 71: “Según mi pésima costumbre, en casos tales, mi temperamento me llevó a tomar la palabra y, con vehemencia quizás excesiva, arremetí contra los tres catalanes, queriendo demostrarles [...] que por tal camino se iba derecho a la guerra civil, que era lo contrario de la República que buscábamos. / Se generalizó la discusión. Intervinieron muchos, pero destacadamente Prieto, que en su patria chica tenía entonces como enemigos irreconciliables a los nacionalistas vascos, y que veía que para ellos los acuerdos con los catalanes tendrían fuerza de ley. / Lo que sostuvimos los no catalanes, y lo que en definitiva prevaleció, con el voto unánime, es decir, incluso los de los catalanes (cursiva del autor), fue que la República no podía contraer más compromiso previo con Cataluña que el de llevar al Parlamento Constituyente un Estatuto de Autonomía, siempre y cuando el pueblo catalán, consultado mediante elecciones libres, declarase que deseaba esa autonomía [...]”. El entonces presidente del Gobierno español define las exigencias catalanistas de manera mucho más terminante, $c f r$. BERENGUER, Dámaso, De la Dictadura a la República (Madrid, Tebas, 1975), p. 165: "los catalanes [...] pedían la independencia de Cataluña como premio a su colaboración para derribar el Régimen [...]”.

${ }^{9}$ Canosa, Francesc, Entre el sabre i la bomba. Memòries d'un país i d'un partit: Unió Democràtica de Catalunya. (1931-1980) (Barcelona, A Contra Vent Editors, 2012), pp. 34 y ss.

${ }^{10}$ SALES, Joan, Cartes a Màrius Torres (Tercera edició augmentada amb cartes inèdites a Mercè Figueres, Barcelona, Club Editor, 2014), p. 218.

${ }^{11}$ Alcalá-Zamora, Niceto, La victoria republicana. 1930-1931. El derrumbe de la monarquia y 
lo que concernía a Manuel Carrasco i Formiguerá y a Jaume Ayguader i Miró, así era, en efecto, y ambos habrían de hacer siempre honor a su compromiso. Pero muy pronto todos los presentes en San Sebastián habrían de descubrir que, en la misma buena lógica, quienes en modo alguno se sentían partícipes del nuevo orden constitucional republicano tampoco se mostrarían inclinados a acatarlo. Más bien, y desde el 14 de abril de 1931, habrían de trabajar para dinamitarlo.

Pero es el propio Manuel Carrasco i Formiguera quien, como autor del único libro monográfico sobre El Pacto de San Sebastián elaborado por alguno de los asistentes a la histórica reunión, nos facilita un imprescindible testimonio sobre la materia, en donde, y desde el principio, quiere dejar claro que la voluntad de los representantes catalanes en la reunión de San Sebastián no había sido otra que evitar precisamente que el sentimiento separatista se extendiera en Cataluña, entendiendo el separatismo como "un sentimiento, una ilusión, un deseo inconsciente", es decir, un sentimiento que se imponía "por la imposibilidad de soluciones armónicas del problema de Cataluña”.

A este respecto, el jurista barcelonés habría de resumir sus reflexiones con una afirmación -por no denominarla sentencia- enteramente vigente en Cataluña y en España en 1932, cuando compuso su libro, pero con toda certeza también si se pretende entender el debate territorial español en 2021: "los catalanes serán separatistas siempre que hayan de dejar de ser catalanes para ser españoles". Y añadía que la separación no tendría razón de ser cuando los catalanes pudieran "articular Cataluña" y ser catalanes, y sobre todo catalanes dentro de una estructura española, "o mejor ibérica". Con estas premisas, puede perfectamente entenderse el pleno respaldo que los delegados de las fuerzas catalanistas presentes en San Sebastián prestaron al compromiso de resolución de la cuestión catalana finalmente adoptado:

"Primer. Els reunits a Sant Sebastià reconegueren unànimement la realitat viva del problema de Catalunya i convingueren per tant que el triomf de la Revolució suposava en el mateix el reconeixement de la personalitat de Catalunya i el compromis per parte del Govern revolucionari de donar una solució jurídica al problema català.

Segon. La solució del problema hauria de tenirper base i fonament la voluntat de Catalunya expresada en un projecte d'Estatut o Constituciò autònoma proposada lliurement per el poble

el triunfo de una revolución pacifica (Madrid, La Esfera de los Libros, 2012), pp. 102-103: “[...] la distinción para el régimen autonómico entre la vida interior de Cataluña, peculiar, determinada por su voluntad, registrada no más por el Parlamento Español y la vida de relación con las distintas regiones, que no pudiendo ser las obras porque sería la imposición de una solo, tenía que regularse conocidas las aspiraciones de ella, por el general consentimiento de las Cortes Constituyentes, cuya ulterior decisión, evidentemente amplia y justa, no podíamos prejuzgar ni cohibir. Quedó convenido que el Estatuto Catalán se formara en la región, se sometiera al plebiscito de ayuntamientos y ciudadanos y tal ponencia se presentara por el gobierno a la definitiva deliberación de las Constituyentes. El acuerdo y las aclaraciones que lo habían precedido y explicado [...] no se escribieron en parte alguna, y fue la lealtad y el honor de todos respetarlo sustancial y fielmente entre la agitación difícil y tentadora de un período revolucionario". Se había alcanzado un acuerdo político, y no intelectual, cfr. PRiETo, Indalecio, Palabras al viento. (Barcelona. 1992), pp. 109 y ss. 
de Catalunya i acceptada per la voluntat de la majoria dels catalans expresada en referéndum votem per sufragi universal.

Tercer. L'Estatut proposat i votat per Catalunya hauria d'ésser sotmès, en la part referent a la delimitació d'atribucions entre el Poder Central $i$ el Govern autònom de Catalunya, a l'aprovació sobirana de les Corts Constituents"12.

También de acuerdo con el testimonio de Manuel Carrasco i Formiguera, por nadie desmentido, uno de los principios definidores del modelo constitucional adoptado por la Constitución de 9 de diciembre de 1931, el derecho al autogobierno político de las regiones dentro de un Estado integral, y sin fractura de la clásica concepción de la soberanía nacional, fue ya diseñado, y además de manera muy nítida, y con mucha propiedad en su concepción y en su expresión política, institucional, normativa y constitucional, en San Sebastián el 17 de agosto de 1930. Y, de acuerdo con los términos enunciados por el jurista democristiano asesinado en Burgos el 9 de abril de 1938, suponer que la reunión celebrada por las fuerzas republicanas en San Sebastián se había circunscrito, y ello ya resultaría sumamente relevante, a la conformación de un gabinete provisional que pudiera asumir de manera inmediata el poder ejecutivo cuando las urnas o un proceso revolucionario así lo determinaran, sería desconocer el impacto constituyente del mucho más amplio acuerdo alcanzado. Político, sin duda; pero también jurídico y, por lo tanto, histórico.

Miguel Maura, sin embargo, no atribuye al pacto suscrito en la capital donostiarra la misma precisión jurídica de la que, por cierto, en todo momento de su carrera pública, hace gala el futuro conseller de Unió Democràtica de Catalunya. Con el sentido práctico y ejecutivo que siempre habría de caracterizarle (dos horas tardó, en la tarde-noche del 14 de abril de 1931, ya como flamante ministro de la Gobernación, en poner a las órdenes del Gobierno provisional a todos los gobernadores civiles de España, o en conminarles a entregar sus atribuciones al Comité Revolucionario provincial si es que le presentaban la renuncia, algo a lo que no procedió precisamente la mayoría), Miguel Maura afirma que, cerrado el debate sobre Cataluña se pasó de inmediato "al examen del plan político", que consistió en la preparación del "movimiento revolucionario", entendido como "arma de desgaste y señal de alarma para los gobernantes", constituyéndose un Comité ejecutivo que habría de presidir Niceto Alcalá-Zamora, y del que formarían parte Indalecio Prieto, Manuel Azaña, Fernando de los Ríos, Marcelino Domingo, Álvaro de Albornoz y el propio Miguel Maura, un comité ejecutivo que habría de ser el núcleo tanto del futuro Comité revolucionario como del Gobierno provisional del 14 de abril de 1931, ya con la inclusión del líder del socialismo español, el madrileño Francisco Largo Caballero, definitivamente incorporado al

${ }^{12}$ Carrasco i Formiguera, Manuel, El pacte de San Sebastià (Barcelona, Inehca, 2013), pp. 24-25 y 29-30. Hay que señalar que Jaime Ayguadér habría de atribuirse también la autoría de la célebre intervención en defensa de la personalidad política de Cataluña, vid. AyguAder i MirÓ, Jaume, Catalunya i la revolució (Barcelona, La Sageta, 1932), pp. 81 y ss. No obstante, todos los restantes asistentes a la reunión en el local de la Unión Republicana que aportan su testimonio, adjudican todo el protagonismo al abogado nacido en el Carrer Pelai de Barcelona. 
movimiento ${ }^{13}$. La interpretación del Pacto de San Sebastián iniciaba un itinerario controvertido. Pero no como consecuencia de su impacto en el tránsito político de la Monarquía a la República, o de la dictadura a la democracia, sino en atención a su contenido constituyente. Los principios inspiradores de la futura Constitución republicana quedaban ya significativamente mediatizados por los acuerdos políticos alcanzados en San Sebastián.

\section{El NACIMIENTO DE UNA CONTROVERSia POLÍTICA E} HISTÓRICO-JURÍDICA

De hecho, una reunión, como la del 17 de agosto de 1930, convocada y liderada por la Derecha Liberal Republicana, habría de contar con un muy escueto documento a manera de acta por obra del entusiasmo de un socialista asistente a la reunión a título personal: Indalecio Prieto. Fue el propio periodista nacido en Oviedo quien en una mesa del "Bar España", próximo a la sede de Unión Republicana en la calle Garibay, procedió a la redacción de una suerte de conclusiones en donde, además de enumerar a los asistentes y a las fuerza partidarias representadas (incluyendo al Partido Federal, aclarando que "en espera de acuerdos de su próximo Congreso, no puede enviar ninguna delegación”) en apenas una docena de líneas daba cuenta de los resultados de unas deliberaciones que habrían de transformar para siempre la historia de España ${ }^{14}$.

Indalecio Prieto había optado por transmitir a la opinión pública la información indispensable (o menos) y obviar toda referencia concreta, no digamos toda la referencia, al debate territorial. Manuel Azaña habría de recordar con posterioridad cómo se encontró a Indalecio Prieto la mañana del 27 de mayo de 1932 en cuya tarde pronunció en las Cortes su impresionante discurso (de tres horas) sobre Cataluña y su Estatuto, y el entonces ministro de Obras Públicas le manifestó su preocupación con el Estatuto catalán, entendiendo que el nacionalismo vasco no habría de aceptar seguidamente un Estatuto inferior en competencias, lo que

\footnotetext{
${ }^{13}$ Maura, Miguel, cit. (n. 4), p. 72: "No hubo más ni hubo menos en aquella famosa sesión, y con lo que hubo bastó para que pudiera nacer el Gobierno Provisional, para que se diera a la República la tónica que inspiró sus primeros y -más peligrosos- meses de su vida; para que prevaleciera más tarde, en el seno de los partidos y de las organizaciones obreras, merced a la actitud de sus dirigentes, el deseo de apartarse de toda violencia llegada la hora de la victoria". Vid. igualmente Largo Caballero, Francisco, Mis recuerdos. Cartas a un amigo (México. D. F., Ediciones Unidas, S. A., 1976), pp. 98-99.

${ }^{14}$ De Guzmán, Eduardo, cit. (n. 2), p. 324: "Examinada la actual situación política, todos los representantes concurrentes llegaron, en la exposición de sus peculiares puntos de vista, a una perfecta coincidencia, la cual quedó inequívocamente confirmada en la unanimidad con que se tomaron las diversas resoluciones adoptadas. / La misma absoluta unanimidad hubo al apreciar la conveniencia de gestionar rápidamente y con ahínco la adhesión de las demás organizaciones políticas y obreras que en el acto previo de hoy no estuvieron representadas para la finalidad concreta de sumar su poderoso auxilio a la acción que, sin desmayos, pretenden emprender conjuntamente las fuerzas adversas al actual régimen político". Y ello entendiendo su programa de restablecimiento del sistema constitucional quebrantado por el Directorio a partir del 13 de septiembre de 1923, vid. Martínez Barrio, Diego, Memorias (Barcelona, Planeta, 1983), p. 20.
} 
significaría que "la enseñanza caería en manos de los nacionalistas católicos"15. Como habría de ponerse después de manifiesto, Prieto se equivocaba. Porque la excepcional posición constitucional ganada por Cataluña en el Pacto de San Sebastián habría de verse consolidada en el ordenamiento político y territorial de la Segunda República. ¿Acaso nos encontramos, también, ante el precedente de la distribución estratégica de papeles entre nacionalismos periféricos que habría de materializarse en la redacción del texto constitucional de 1978, cuando el catalanismo adoptó una activa presencia en la propia ponencia constitucional a través de la figura de Miquel Roca i Junyent, hijo de Joan Baptista Roca i Caball, uno de los fundadores de la propia Unió?

Manuel Carrasco i Formiguera no tenía la menor duda acerca de la impronta constituyente de los acuerdos adoptados en San Sebastián. Para el jurista barcelonés, su aplicación por el Gobierno provisional de la República venía a dar satisfacción a la aspiración de Cataluña de "ser libre dentro de una República federal española, o dentro de un pacto de federación con los restantes pueblos hispánicos". Y trazaba una nítida distinción entre la situación catalana antes y después de la proclamación de la República, sosteniendo que "Cataluña, que fue separatista de todas las vergüenzas de la España monárquica y dictatorial, desea, anhela, confía hoy, abrazar estrechamente a todos los pueblos hermanos de España dentro de un régimen republicano de unidad basado en la libertad"16. El planteamiento político, jurídico y constitucional aprobado por todos los delegados republicanos reunidos en el local de la Unión Republicana de San Sebastián habría de aplicarse fielmente en el Estatuto catalán de 1932. Cabría incluso preguntarse, una vez más, si no se trataría de un planteamiento que habría de atesorar toda su vigencia cuando, más de cuatro décadas después, se abrió un nuevo período constituyente en España.

Pero, seguramente, la mejor síntesis de las motivaciones de los grandes inspiradores intelectuales da la reunión, de su concepción y de su espíritu, no pudo ser obra sino de Miguel Maura, quien un tercio de siglo después habría de rememorar los verdaderos objetivos, y objetivos sin duda constituyentes, en el procedimiento y en el estilo, muy prontamente en el ámbito político e institucional, plasmados en el Pacto de San Sebastián: "Era indispensable, si se quería hacer labor útil y ordenada, aunar voluntades y reunir todos los elementos capaces de actuar, no sólo por el camino de la revolución en el que, dicho sea de paso, creíamos muy poco tanto él (Alcalá-Zamora) como yo, conocedores de la forma en que suelen desarrollarse gracias a los elementos militares comprometidos esas tragicomedias, sino también por el de la ciudadanía [...]"17.

El general Emilio Mola, sin embargo, sostiene en el último volumen de sus memorias, El derrumbamiento de la Monarquía, que el Comité Revolucionario en absoluto confiaba en alcanzar los objetivos planteados por Miguel Maura de aunar

${ }^{15}$ AzAÑa, Manuel, Memorias políticas y de guerra (Barcelona, Crítica, 1978), I, pp. 473-474.

${ }^{16}$ Carrasco i Formiguera, Manuel, cit. (n. 12), p. 46. Traducción del original catalán por el autor. No era de la misma opinión el histórico líder de la Lliga, cfr. CAMBÓ, Francesc, Memorias (1876-1936) (Madrid, Alianza, 1987), p. 437: "se votó contra todo lo establecido".

${ }^{17}$ Maura, Miguel, cit. (n. 4), p. 69. 
unas voluntades sumamente plurales por su identidad y procedencia para evitar "el camino de la revolución", y su confianza en el resultado de las elecciones municipales del 12 de abril de 1931 era lo bastante limitada como para contemplar el casi inmediato emprendimiento de acciones revolucionarias ${ }^{18}$.

Niceto Alcalá-Zamora tercia en este histórico debate entre sus contemporáneos para presentar el advenimiento de la República como el inevitable resultado de un proceso histórico profundo, casi un movimiento telúrico que se encontraba únicamente necesitado de un lector, intérprete y líder. Y, como es natural, de acuerdo con su óptica, ese movimiento habría de encontrar ese imprescindible líder en él mismo. Pero cabe añadir que, en esta ocasión, el jefe de Estado nacido en Priego de Córdoba abandona su estilo exuberante para modelar un análisis histórico-constitucional sumamente sintético y asertivo en sus conclusiones. Aunque se trate de unas conclusiones que él mismo protagonice: " [...] Lo que yo hice estaba al alcance de muchos a quienes faltó la visión, el ánimo, las fuerzas y quizás sobre todo la fe en el pueblo. Porque la gran división abierta entre la dictadura y mostrada con realce en las características de superioridad sentimental entre las Cortes Constituyentes de la Republica y otros Parlamentos de nivel general quizás más formado y culto está precisamente en eso: a un lado los que hemos conservado la fe en la energía popular como fuerza curativa y al otro los escépticos. Pudiera decirse que la restauración monárquica, hecha por Cánovas de 1875 a 1876, fue la ficción de un espíritu genial pero escéptico, mientras que la revolución por mí organizada de 1930 a 1931 es la obra de una voluntad modesta, pero que no temió a las realidades por conservar la fe en las vicisitudes del pueblo"19.

Joan Sales comenzaba la segunda parte de su novela cumbre, Incierta gloria, con una cita de Simone Weil: "la desgracia es ridícula". Los términos de análisis a los que acude quien fuera el primer presidente de la Segunda República para confrontar el proceso constituyente republicano con el proceso constituyente de la Restauración, y a él mismo con Antonio Cánovas del Castillo, y además prevalecer ambos, el proceso y él, se diría, no se encuentran exentos de la voluntad decidida de escapar a esa suerte de sentimiento fatídico que tiende a sobrevolar sobre la historia de España, y muy especialmente sobre su historia constitucional, desde el proceso constitucional gaditano. Y de no resignarse ni sucumbir a la desgracia.

En una España en la que confluían en plena fecundidad las generaciones de 1898 y de 1914, y el grupo poético de 1927, como umbral de un segundo Siglo de Oro de la cultura española superador por muchos conceptos del primero de ellos, al jurista cordobés le faltaba la siempre imprescindible sensibilidad histórica y la no menos exigible grandeza de los hombres de Estado, o ambas, para no captar que él mismo, o Miguel Maura, y con ellos todos los asistentes a la reunión celebrada en la sede de la Unión Republicana de San Sebastián el 17 de agosto de 1930, eran el mejor testimonio de la esencial continuidad de un mismo proyecto

\footnotetext{
${ }^{18}$ Mola Vidal, Emilio, El derrumbamiento de la Monarquía. Memorias de mi paso por la Dirección General de Seguridad (Madrid, Librería Bergua, 1933), p. 25: "Ahora bien, a pesar del optimismo revolucionario, no se creyó nunca en obtener un éxito rotundo en las elecciones; prueba de ello es que se persistía en la idea de acudir a la violencia [...]".

${ }^{19}$ Alcalá-Zamora, Niceto, cit. (n. 11), pp. 70-71.
} 
histórico de nación, pero también de expresión del proyecto de establecimiento de un Estado de Derecho que, en primer lugar, proponía una manera democrática de vivir, es decir: respeto y compromiso por y con el proyecto de vida del otro, bajo el imperio de la ley.

De tránsito pacífico, en paz, concordia y unidad, hacia esa manera democrática de vivir. En varias ocasiones en la historia de España ese tránsito pacífico se produjo. Y, también, en varias ocasiones en la historia del España, cuando se dejó de entender que democracia es, en primer lugar, manera democrática de vivir, la paz cívica se quebró. Miguel Maura y Manuel Carrasco i Formiguera, casi constituyentes ya en 1930, a su pesar el abogado madrileño, y con plena conciencia su colega barcelonés, lo entendieron muy bien. De su debate apasionado, y de su controversia llena de convicción, emergió uno de los procesos institucionales más apasionantes en la historia del constitucionalismo español.

\section{BiBLIOGRAFíA}

Alcalá-Zamora, Niceto, La victoria republicana. 1930-1931. El derrumbe de la monarquía y el triunfo de una revolución pacífica (Madrid, La Esfera de los Libros, 2012).

Ayguader i Miró, Jaume, Catalunya i la revolució (Barcelona, La Sageta, 1932).

Azaña, Manuel, Memorias políticas y de guerra (Barcelona, Crítica, 1978), I.

Berenguer, Dámaso, De la Dictadura a la República (Madrid, Tebas, 1975).

CAmbÓ, Francesc, Memorias (1876-1936) (Madrid, Alianza, 1987).

CANOSA, Francesc, Entre el sabre i la bomba. Memòries d'un país i d'un partit: Unió Democràtica de Catalunya (1931-1980) (Barcelona, A Contra Vent Editors, 2012).

Carrasco i Formiguera, Manuel, El pacte de San Sebastià (Barcelona, Inehca, 2013). DE GuZMán, Eduardo, 1930. Historia política de un año decisivo (Madrid, Tebas, 1973).

Duque de Maura; Fernández Almagro, Melchor, Por qué cayó Alfonso XIII (Madrid, Ediciones Ambos Mundos S. L., 1948).

Largo Caballero, Francisco, Mis recuerdos. Cartas a un amigo (México D. F., Ediciones Unidas S. A., 1932).

Lerroux, Alejandro, La pequeña historia (Madrid, Afrodisio Aguado S. A. 1963).

Martínez Barrio, Diego, Memorias (Barcelona, Planeta, 1983).

Maura, Antonio, Treinta y cinco años de vida pública (Madrid, Biblioteca Nueva, 1954).

Maura, Miguel, Así cayó Alfonso XIII (Barcelona, Ariel, 1966).

Mola Vidal, Emilio, El derrumbamiento de la Monarquía. Memorias de mi paso por la Dirección General de Seguridad (Madrid, Librería Bergua, 1933).

-Obras completas (Madrid, Librería Santarén, 1940).

PLA, Josep, Dietarios de Madrid. Madrid. 1921. El advenimiento de la II República (Barcelona, Destino, 2020).

Prieto, Indalecio, Palabras al viento (Barcelona, Fundación Indalecio Prieto/Planeta, 1992).

SALES, Joan, Cartes a Màrius Torres (Tercera edició augmentada amb cartes inèdites a Mercè Figueres, Barcelona, Club Editor, 2014).

SÁnchez Guerra, Rafael, Proceso de un cambio de régimen (Historia y murmuración) (Madrid, Compañía Ibero\&Americana de Publicaciones, S. A., 1932). 